\title{
Atmospheric behaviors of particulate-bound polycyclic aromatic hydrocarbons and nitropolycyclic aromatic hydrocarbons in Beijing, China from 2004 to 2010
}

\author{
Ning Tang ${ }^{\text {a, }}$, Genki Suzuki ${ }^{\text {b }}$, Hiroshi Morisaki ${ }^{\text {b }}$, Takahiro Tokuda ${ }^{c}$, Xiaoyang Yang ${ }^{\text {d }}$, \\ Lixia Zhao ${ }^{\mathrm{e}}$, Jinming Lin ${ }^{\mathrm{f}}$, Takayuki Kameda ${ }^{\mathrm{g}}$, Akira Toriba ${ }^{\mathrm{b}}$, Kazuichi Hayakawa ${ }^{\mathrm{a}}$ \\ a Institute of Nature and Environmental Technology, Kanazawa University, Kakuma-machi, Kanazawa 920-1192, Japan \\ ${ }^{\mathrm{b}}$ Institute of Medical, Pharmaceutical and Health Sciences, Kanazawa University, Kakuma-machi, Kanazawa 920-1192, Japan \\ c Ishikawa Prefectural Institute of Public Health and Environmental Science, 1-11, Taiyogaoka, Kanazawa 920-1154, Japan \\ ${ }^{\mathrm{d}}$ Atmospheric Chemistry \& Aerosol Division, Chinese Research Academy of Environmental Sciences, No. 8, Dayangfang, Anwai, Beijing 100012, China \\ e State Key Laboratory of Environmental Chemistry and Ecotoxicology, Research Center for Eco-Environmental Sciences, Chinese Academy of Sciences, \\ Beijing 100085, China \\ ${ }^{\mathrm{f}}$ Department of Chemistry, Tsinghua University, Beijing 100084, China \\ ${ }^{g}$ Graduate School of Energy Science, Kyoto University, Gokasho, Uji 611-0011, Japan
}

\section{H I G H L I G H T S}

- Atmospheric PAHs and NPAHs were investigated in Beijing from 2004 to 2010.

- The PAH and NPAH levels decreased in heating season during our study periods.

- High wind speed can remove the PAHs and NPAHs in the heating season.

- High relative humidity can remove the PAHs and NPAHs in the non-heating season.

- Source control measures also helped to reduce air pollution in Beijing.

\section{A R T I C L E I N F O}

\section{Article history:}

Received 2 October 2016

Received in revised form

30 December 2016

Accepted 31 December 2016

Available online 3 January 2017

\section{Keywords:}

PAHs

NPAHs

Air pollution

Source control measure

Beijing

\begin{abstract}
A B S T R A C T
Airborne particulates were collected at an urban site (site 1) from 2004 to 2010 and at a suburban site (site 2) in 2010 in Beijing. Nine polycyclic aromatic hydrocarbons (PAHs) and five nitropolycyclic aromatic hydrocarbons (NPAHs) in the airborne particulates were determined by HPLC with fluorescence and chemiluminescence detection, respectively. The concentrations of PAHs and NPAHs were higher in heating season than in non-heating season at the two sites. Both the concentrations of PAHs and NPAHs decreased in the non-heating season but only the concentrations of NPAHs decreased in heating season at site 1, from 2004 to 2010 . These findings suggest that source control measures implemented by the city of Beijing helped to reduce air pollution in Beijing. The concentrations of PAHs increased at site 1 in 2010, possibly because of the transport of emissions from windward other areas, such as Shanxi province. Several diagnostic ratios of PAHs and NPAHs showed that the different sources contributed to Beijing's air pollution, although coal combustion was the main source in the heating season and vehicle emission was the main source in the non-heating season. An analysis of physical parameters at Beijing showed that high wind speed can remove atmospheric PAHs and NPAHs in the heating season and that high relative humidity can remove them in the non-heating season.
\end{abstract}

๑ 2017 Elsevier Ltd. All rights reserved.

\section{Introduction}

Polycyclic aromatic hydrocarbons (PAHs) are a group of organic

\footnotetext{
* Corresponding author.

E-mail address: n_tang@staff.kanazawa-u.ac.jp (N. Tang).
}

compounds consisting of two or more fused benzene rings, and nitropolycyclic aromatic hydrocarbons (NPAHs) are their nitrated derivatives. PAHs and NPAHs are ubiquitous environmental pollutants. Atmospheric PAHs and NPAHs mainly originate from imperfect combustion and pyrolysis of organic matters, although some NPAHs are formed in the atmosphere via reactions of their 
parent PAHs such as 2-nitropyrene and 2-nitrofluoranthene (Arey et al., 1986; Hayakawa et al., 1995; Rogge et al., 1993). PAHs and NPAHs exist in both the gas and particle phases in the atmosphere, and their gas/particulate partition depend on factors such as the vapor pressure, temperature and the concentration and properties of dust (Araki et al., 2009; Sitaras et al., 2004; Yamasaki et al., 1982). In urban areas, PAHs and NPAHs are mainly emitted from automobiles, power plants, domestic heating and industrial processes (Gachanja and Worsfold, 1993; Kavouras et al., 2001; Tang et al., 2005). Many PAHs and NPAHs have carcinogenic and/or mutagenic properties (Ames et al., 1975; Epstein et al., 1979). Benzo[a] pyrene (BaP) and 1-nitropyrene (1-NP) are categorized in groups 1 (carcinogenic to humans) and 2A (probably carcinogenic to humans), respectively (IARC, 2013). Several PAHs also exhibit estrogenic, antiestrogenic, antiandrogenic activities (Kizu et al., 2000) or reactive oxygen species producing activity (Motoyama et al., 2009). In addition, prenatal exposure to PAHs could impact cognitive development and learning ability (Perera et al., 2012).

In recent years the consumption of petroleum and coal has grown considerably in China, resulting in serious environmental problems. Our previous studies have reported the following results on atmospheric PAHs and NPAHs in three cities in the Northeast China: (1) The mean concentrations of PAHs and NPAHs in particulate matter were in the order Fushun $>$ Tieling $>$ Shenyang, even though greater amounts of petroleum and coal are consumed in Shenyang (Hattori et al., 2007). (2) Molecular diagnostic ratios of several PAHs and NPAHs showed that the major contributors of PAHs and NPAHs were coal combustion systems both in summer and winter in Fushun and Tieling and in winter in Shenyang (Hattori et al., 2007). (3) In Shenyang, the mean concentrations of PAHs in winter 2007 decreased significantly from the concentrations in winter 2002 and the mean concentrations of NPAHs in winter did not change markedly between 2001 and 2007. However, both PAH and NPAH concentrations in summer increased from 2001 to 2007. These results suggested that motor vehicles have become one of the major contributors of atmospheric PAHs and NPAHs in Shenyang in both seasons (Tang et al., 2011).

The major sources of atmospheric PAHs in Beijing have been identified as coal combustion systems in winter, long-range transport in spring and motor vehicles in the other seasons (Feng et al., 2005; Hayakawa et al., 2007; He et al., 2006; Hou et al., 2006; Huang et al., 2006; Jiang et al., 2009; Liu et al., 2007; Wang et al., 2008; Zhang et al., 2009; Zhou et al., 2005). However, only a few studies have examined atmospheric NPAHs, whose mutagenicity is much stronger, in Beijing (Li et al., 2015; Lin et al., 2015; Wang et al., 2011). To the best of our knowledge, there have been no reports on the characteristics of mid-to-long term changes in atmospheric PAHs and NPAHs in Beijing. Therefore, in this study, our objectives were to clarify the changes of concentrations, compositions and major contributors of atmospheric PAHs and NPAHs in Beijing from 2004 to 2010, and to identify the causes of these changes.

\section{Experimental}

\subsection{Samplings and characteristics of test sites}

Beijing $\left(39^{\circ} 55^{\prime} \mathrm{N} ; 116^{\circ} 26^{\prime} \mathrm{E}\right)$ is a large city in Asia and is located in the North Temperate Zone. The variations of population, gross domestic product (GDP), energy consumptions and numbers of registered cars during our sampling periods are shown in Table 1 (Beijing Statistical Information Net: http://www.bjstats.gov.cn/ esite/and Beijing Municipal Environmental Monitoring Center: http://www.bjmemc.com.cn). Total suspended particles (TSP) were collected at two sites (Fig. 1), using a high-volume air sampler (HV) at a flow rate of $1000 \mathrm{l} / \mathrm{min}$ (HV-700F, Shibata Sci. Tech., Tokyo, Japan) or an Andersen high-volume air sampler (AHV) at a flow rate of $566 \mathrm{~L} / \mathrm{min}$ (HV-1000R, Shibata Sci. Tech.). Site 1 is located in urban area (No. 18 Shuangqing road, Haidian district) and site 2 is located in suburban area (Shenshan village, Huairou district). Samplings were carried out at site 1 on Dec. 18-31, 2004, Jan. 21 Feb. 2, 2008 and Nov. 25 - Dec. 21, 2009 (heating season), and on May 9-24, 2005, Aug. 21 - Sep. 2, 2007 and Aug. 11 - Sep. 1, 2010 (non-heating season); and at site 2 on Jan. 20-31 (heating season) and Aug. 2-16, 2010 (non-heating season). A summary of meteorological conditions during the sampling periods is provided in Table 2 (The data of average temperature, dew point, wind speed and visibility in Beijing during the sampling periods were obtained from National Climatic Data Center, NOAA and average humidity were calculated by using the data of average temperature and dew point). AHV was used only to collect TSP in five fractions according to their aerodynamic size at site 1 in 2009 and 2010. TSP were collected on quartz fiber filters (2500QAT-UP, Pallflex Products,

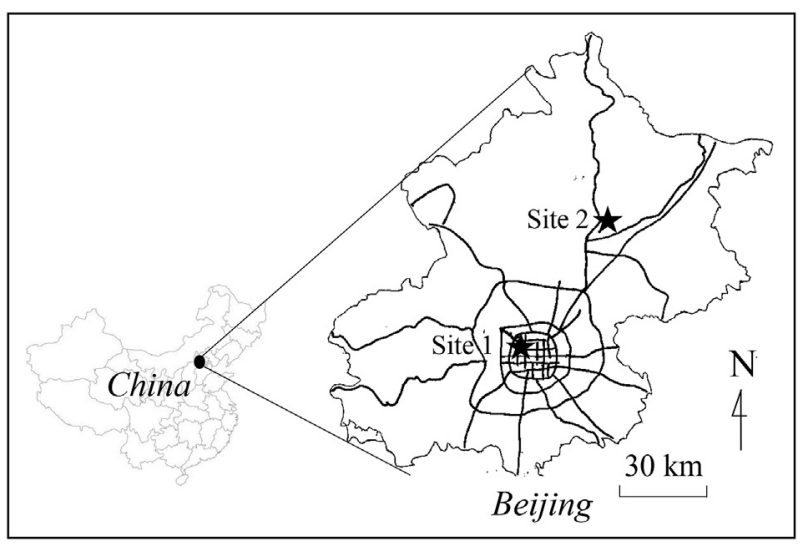

Fig. 1. Map of Beijing $\left(39^{\circ} 55^{\prime} \mathrm{N} ; 116^{\circ} 26^{\prime} \mathrm{E}\right)$ with air sampling sites. Site 1 : an urban site located at No. 18 Shuangqing Road, Hiadian District. Site 2: a suburban site located at Shenshan Village, Huairou District.

Table 1

Population, gross domestic product (GDP), energy consumptions and numbers of registered cars, ${ }^{\mathrm{a}}$ and $\mathrm{PM}_{10}, \mathrm{SO}_{2}$ and $\mathrm{NO}_{2}$ levels ${ }^{\mathrm{b}}$ in Beijing from 2004 to 2010 .

\begin{tabular}{|c|c|c|c|c|c|c|c|}
\hline \multirow[t]{2}{*}{ Year } & \multirow{2}{*}{$\frac{\text { Population }}{\left(\mathrm{X} 10^{4}\right)}$} & \multirow{2}{*}{$\frac{\text { GDP }}{\text { (billion yuan) }}$} & \multirow{2}{*}{$\frac{\text { Energy consumptions }}{\text { (million tonnes coal equivalent) }}$} & \multirow{2}{*}{$\frac{\text { No. of cars }}{\left(\mathrm{X} 10^{4}\right)}$} & $\mathrm{PM}_{10}$ & $\mathrm{SO}_{2}$ & $\mathrm{NO}_{2}$ \\
\hline & & & & & \multicolumn{3}{|l|}{$\overline{\left(\mu \mathrm{g} / \mathrm{m}^{3}\right)}$} \\
\hline 2004 & 1493 & 428.3 & 51.4 & 187 & 0.149 & 0.055 & 0.071 \\
\hline 2005 & 1538 & 697.0 & 55.0 & 215 & 0.142 & 0.050 & 0.066 \\
\hline 2006 & 1581 & 811.8 & 59.1 & 244 & 0.161 & 0.053 & 0.066 \\
\hline 2007 & 1633 & 984.7 & 62.9 & 278 & 0.148 & 0.047 & 0.066 \\
\hline 2008 & 1695 & 1112 & 63.4 & 318 & 0.122 & 0.036 & 0.049 \\
\hline 2009 & 1755 & 1215 & 65.8 & 402 & 0.121 & 0.034 & 0.053 \\
\hline 2010 & 1961 & 1378 & 69.5 & 481 & 0.121 & 0.032 & 0.057 \\
\hline
\end{tabular}

a Beijing Statistical Information Net (http://www.bjstats.gov.cn/esite/).

b Beijing Municipal Environmental Monitoring Center (http://www.bjmemc.com.cn). 
Table 2

Meteorological conditions in Beijing during the sampling periods.

\begin{tabular}{|c|c|c|c|c|c|}
\hline Sampling period & & $\frac{\text { Temperature }}{\left({ }^{\circ} \mathrm{C}\right)}$ & $\frac{\text { Wind speed }}{(\mathrm{m} / \mathrm{s})}$ & $\frac{\text { Relative humidity }}{(\%)}$ & $\frac{\text { Visibility }}{(\mathrm{km})}$ \\
\hline \multicolumn{6}{|l|}{ Site 1} \\
\hline \multirow[t]{3}{*}{ Heating } & Dec. $18-30,2004$ & $-5.3(-7.6 \sim-0.6)$ & $3.1(1.0-6.8)$ & $55.8(29.0-90.3)$ & $4.3(1.1-6.4)$ \\
\hline & Jan. 21 - Feb. 2, 2008 & $-4.1(-6.7 \sim-2.3)$ & $4.0(1.5-6.7)$ & $30.1(22.7-62.4)$ & $5.7(4.0-6.5)$ \\
\hline & Nov. 25 - Dec. 21, 2009 & $-5.5(-7.2 \sim-4.8)$ & $3.3(1.1-8.3)$ & $47.1(17.1-83.4)$ & $2.9(0.9-4.5)$ \\
\hline \multirow[t]{3}{*}{ Non-heating } & May 9-24, 2005 & $18.9(11.5-23.6)$ & $3.2(2.5-4.4)$ & $54.6(30.6-87.5)$ & $4.6(2.7-6.0)$ \\
\hline & Aug. 21 - Sep. 2, 2007 & $26.0(22.2-30.2)$ & $2.5(1.9-3.5)$ & $62.3(51.2-89.3)$ & $4.7(3.4-6.2)$ \\
\hline & Aug. 11 - Sep. 1, 2010 & $25.3(20.1-29.5)$ & $2.6(1.7-5.3)$ & $67.9(28.7-87.4)$ & $3.0(1.0-4.2)$ \\
\hline \multicolumn{6}{|l|}{ Site 2} \\
\hline Heating & Jan. 20-31, 2010 & $-1.8(-5.5-2.9)$ & $5.0(1.8-8.5)$ & $29.3(17.5-44.9)$ & $3.9(2.6-4.2)$ \\
\hline Non-heating & Aug. 2-16, 2010 & $26.6(24.1-29.5)$ & $2.8(1.6-5.7)$ & $61.9(28.7-85.1)$ & $2.8(1.2-4.2)$ \\
\hline
\end{tabular}

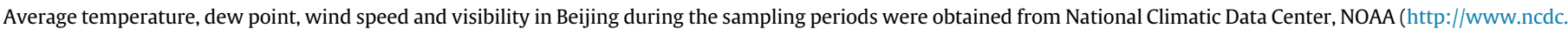
noaa.gov/) and average humidity were calculated by using the data of average temperature and dew point.

Putnam, CT, U. S. A.). HV filters were replaced every day. AHV filters were replaced 2 times in every week ( 2 and 5 days) during nonheating season campaign but were replaced every 2 days during heating season sampling campaign because the TSP and reactive gases $\left(\mathrm{SO}_{2}, \mathrm{NO}_{2}\right.$ etc.) concentrations were higher in winter. Totally 98 samples were obtained. After being dried in a desiccator in the dark, the filters were weighed and then stored in a refrigerator $\left(-20^{\circ} \mathrm{C}\right)$ until use.

\subsection{Chemicals}

USEPA 610 PAHs mix including fluoranthene (FR), pyrene (Pyr), benz[a]anthracene $(\mathrm{BaA})$, chrysene $(\mathrm{Chr})$, benzo[ $b]$ fluoranthene $(\mathrm{BbF})$, benzo[ $k]$ fluoranthene $(\mathrm{BkF}), \mathrm{BaP}$, benzo[ghi]perylene $(\mathrm{BgPe})$ and indeno[1,2,3-cd]pyrene (IDP) were purchased from Supelco Park (Bellefonte, PA, USA). Pyrene- $d_{10}\left(\mathrm{Pyr}-d_{10}\right)$ and benzo[a]pyrene- $d_{12}\left(\mathrm{BaP}-d_{12}\right)$, internal standards for PAHs, were purchased from Wako Pure Chemicals (Osaka, Japan). 1,3-, 1,6-, 1,8dinitropyrenes (DNPs), 9-nitroanthracene (9-NA), 1-NP, and 2fluoro-7-nitrofluorene (FNF), internal standard for NPAHs, were purchased from Chiron AS (Trondheim, Norway). All other chemicals used were of analytical reagent grade.

\subsection{Pretreatment of samples}

A piece of each HV sample containing about $10 \mathrm{mg}$ of TSP and one-fourth of each five-layer filter of AHV sample was cut into small $(0.5 \mathrm{~cm})$ pieces, which were placed in a flask. Both PAHs and NPAHs were extracted ultrasonically twice with benzene/ethanol $(3: 1, \mathrm{v} / \mathrm{v})$ and then the solution was filtered through a filter paper (Advantec, Toyo No. 6, Toyo Roshi Kaisha, Ltd., Tokyo, Japan). Internal standards, Pyr- $d_{10}$, BaP- $d_{12}$ for PAHs and FNF for NPAHs were added to the flask prior to the ultrasonic extraction. The organic solution was washed once with $5 \%(\mathrm{w} / \mathrm{v})$ sodium hydroxide solution, once with $20 \%(\mathrm{v} / \mathrm{v})$ sulfuric acid solution and twice with water for removing acid and base substance. After filtering the organic solution with an HLC-DISK membrane (pore size $0.45 \mu \mathrm{m}$, Kanto Chemical Co., Tokyo, Japan), $100 \mu \mathrm{L}$ of dimethyl sulfoxide was added and then the organic solution was concentrated to $100 \mu \mathrm{L}$ with rotation evaporator. In the case of $\mathrm{HV}$ sample the concentration was diluted to $1 \mathrm{~mL}$ and in the case of AHV samples the concentration was diluted to $10 \mathrm{~mL}$ with methanol. And then an aliquot ( $20 \mu \mathrm{L}$ for PAHs and $100 \mu \mathrm{L}$ for NPAHs) of the solution was injected into the HPLC systems. Other conditions were the same as in our previous reports (Hayakawa et al., 1991; Tang et al., 2005).

\subsection{HPLC systems for determination of PAHs and NPAHs}

The nine PAHs were determined by using HPLC with fluorescence detection. The PAH HPLC system consisted of a reversedphase column (Inertsil ODS-P, 4.6 i.d. X 250 mm, GL Sciences Inc. Tokyo, Japan) with an acetonitrile/water gradient and fluorescence detection. The flow rate was $1 \mathrm{~mL} / \mathrm{min}$. The time program of the fluorescence detector was set to detect at the optimum excitation and emission wavelengths for each PAH. Other conditions were the same as in our previous report (Tang et al., 2005).

The five NPAHs were determined by using HPLC with chemiluminescence detection. The HPLC system consisted of two reversed-phase columns (Cosmosil 5C18-MS, 4.6 i.d. X (250 + 150) $\mathrm{mm}$, Nacalai Tesque, Tokyo, Japan) connected in series with chemiluminescence detection. The mobile phase was $10 \mathrm{mM}$ imidazole buffer $(\mathrm{pH} 7.6)$-acetonitrile $(1: 1, \mathrm{v} / \mathrm{v})$, and the chemiluminescence reagent solution was an acetonitrile solution containing $0.02 \mathrm{mM}$ bis(2,4,6-trichlorophenly)oxalate and $15 \mathrm{mM}$ hydrogen peroxide. The flow rate was $1 \mathrm{~mL} / \mathrm{min}$ for each solution. Other conditions were the same as in our previous report (Hayakawa et al., 1991; Tang et al., 2003).

\subsection{Quality control and quality assurance}

Quartz fiber filters were used for collecting particulate-bound PAHs and NPAHs. The filters were pre-heated at $600{ }^{\circ} \mathrm{C}$ for $4 \mathrm{~h}$ before using them to lower their PAH and NPAH blank values. The filters before and after collecting TSP were measured at the same temperature $\left(21.5 \pm 1.5{ }^{\circ} \mathrm{C}\right)$ and relative humidity $(50 \pm 5 \%)$ conditions. Field blanks, which accompanied samples to the sampling sites, were used to check for background contamination. No contamination was found during the transport of blank samples.

Standard solutions of PAHs and NPAHs were injected into the analysis systems to verify the methods. The calibration curves of all PAHs and NPAHs showed good linearity $(r>0.995)$. The relative standard deviations $(n=3)$ of all PAHs and NPAHs were less than $5 \%$. Recovery and quantification of individual PAH and NPAH were revised using internal standards: $\mathrm{Pyr}-d_{10}$ for FR, Pyr, BaA and $\mathrm{Chr}$; BaP- $d_{12}$ for BbF, BkF, BaP, BgPe and IDP; FNF for all NPAHs.

\section{Results and discussion}

\subsection{Atmospheric concentrations of PAHs and NPAHs}

Table 3 shows the average concentrations of nine PAHs and five NPAHs in the heating and non-heating seasons at two sites in Beijing from 2004 to 2010. Each figure represents the average value 
Table 3

Concentrations of atmospheric PAHs and NPAHs in Beijing from 2004 to 2010.

\begin{tabular}{|c|c|c|c|c|c|c|c|c|c|}
\hline \multirow[t]{4}{*}{ Compound } & & \multicolumn{6}{|l|}{ Site 1} & \multicolumn{2}{|l|}{ Site 2} \\
\hline & & \multicolumn{3}{|l|}{ Heating } & \multicolumn{3}{|l|}{ Non-heating } & \multirow{3}{*}{$\frac{\frac{\text { Heating }}{\text { Jan. 20-31, }}}{2010(n=7)}$} & \multirow{3}{*}{$\frac{\text { Non-heating }}{\text { Aug. } 2-16,}$} \\
\hline & & Dec. 18-30, & Jan. 21 - Feb. 2, & Nov. 25 - Dec.21, & May 9-24, & Aug. 21 - Sep. 2, & Aug. 11 - Sep. 1, & & \\
\hline & & $2004(n=13)$ & $2008(n=7)$ & $2009(n=7)$ & $2005(n=15)$ & $2007(n=7)$ & $2010(n=7)$ & & \\
\hline \multirow{9}{*}{$\begin{array}{l}\text { PAH } \\
\left(\mathrm{pmol} / \mathrm{m}^{3}\right)\end{array}$} & FR & $193 \pm 154$ & $166 \pm 104$ & $294 \pm 222$ & $9.72 \pm 5.05$ & $5.25 \pm 1.47$ & $2.87 \pm 0.54$ & $252 \pm 99.1$ & $2.82 \pm 0.95$ \\
\hline & Pyr & $188 \pm 139$ & $162 \pm 108$ & $276 \pm 200$ & $8.47 \pm 3.80$ & $4.77 \pm 1.26$ & $2.54 \pm 0.49$ & $252 \pm 108$ & $2.59 \pm 0.67$ \\
\hline & $\mathrm{BaA}$ & $103 \pm 68.0$ & $78.8 \pm 43.6$ & $198 \pm 154$ & $6.09 \pm 1.98$ & $2.78 \pm 0.81$ & $0.84 \pm 0.19$ & $103 \pm 38.2$ & $1.18 \pm 0.33$ \\
\hline & Chr & $100 \pm 62.8$ & $61.7 \pm 33.1$ & $186 \pm 137$ & $9.26 \pm 2.98$ & $4.78 \pm 1.62$ & $1.91 \pm 0.53$ & $134 \pm 50.3$ & $1.69 \pm 0.38$ \\
\hline & $\mathrm{BbF}$ & $71.5 \pm 47.3$ & $69.8 \pm 33.8$ & $91.6 \pm 48.7$ & $15.0 \pm 4.53$ & $11.8 \pm 5.71$ & $4.85 \pm 1.78$ & $33.3 \pm 19.9$ & $2.95 \pm 0.76$ \\
\hline & $\mathrm{BkF}$ & $30.8 \pm 18.8$ & $22.4 \pm 11.2$ & $37.6 \pm 20.9$ & $5.90 \pm 1.87$ & $4.22 \pm 1.32$ & $1.53 \pm 0.39$ & $27.0 \pm 14.0$ & $1.21 \pm 0.36$ \\
\hline & $\mathrm{BaP}$ & $64.4 \pm 41.2$ & $50.7 \pm 30.0$ & $68.6 \pm 37.3$ & $9.05 \pm 3.03$ & $5.37 \pm 1.51$ & $2.00 \pm 0.48$ & $63.6 \pm 35.0$ & $2.05 \pm 0.74$ \\
\hline & $\mathrm{BgPe}$ & $52.1 \pm 31.6$ & $82.1 \pm 41.7$ & $26.1 \pm 27.1$ & $12.4 \pm 3.66$ & $13.3 \pm 3.86$ & $3.22 \pm 0.80$ & $31.1 \pm 18.1$ & $3.42 \pm 0.99$ \\
\hline & IDP & $31.6 \pm 22.0$ & $36.1 \pm 21.7$ & $54.5 \pm 32.6$ & $8.12 \pm 2.24$ & $7.38 \pm 1.81$ & $3.22 \pm 0.89$ & $47.8 \pm 50.9$ & $2.29 \pm 0.96$ \\
\hline \multicolumn{2}{|l|}{ Total PAHs } & $835 \pm 580$ & $730 \pm 421$ & $1230 \pm 862$ & $84.0 \pm 24.6$ & $59.6 \pm 16.2$ & $23.0 \pm 5.59$ & $944 \pm 262$ & $20.2 \pm 4.36$ \\
\hline \multirow{3}{*}{$\begin{array}{l}\text { NPAH } \\
\left(\mathrm{fmol} / \mathrm{m}^{3}\right)\end{array}$} & DNPs & $40.7 \pm 26.7$ & $15.5 \pm 7.00$ & $13.5 \pm 9.17$ & $20.1 \pm 26.7$ & $8.18 \pm 3.76$ & $1.25 \pm 0.30$ & $8.76 \pm 5.78$ & $1.54 \pm 0.43$ \\
\hline & 9-NA & $2070 \pm 1120$ & $1610 \pm 225$ & $1260 \pm 784$ & $1730 \pm 868$ & $705 \pm 216$ & $82.4 \pm 104$ & $2740 \pm 1810$ & $181 \pm 81.4$ \\
\hline & $1-\mathrm{NP}$ & $1084 \pm 997$ & $761 \pm 228$ & $391 \pm 182$ & $76.2 \pm 48.6$ & $92.7 \pm 41.9$ & $48.4 \pm 20.3$ & $203 \pm 72.3$ & $38.2 \pm 18.3$ \\
\hline \multicolumn{2}{|l|}{ Total NPAHs } & $3200 \pm 1320$ & $2390 \pm 460$ & $1480 \pm 900$ & $1820 \pm 890$ & $805 \pm 234$ & $120 \pm 118$ & $2900 \pm 1880$ & $221 \pm 85.1$ \\
\hline
\end{tabular}

All data represent mean \pm standard deviation.

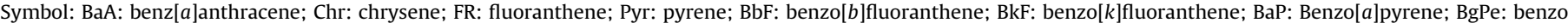
[ghi]perylene; IDP: indeno[1,2,3-cd]pyrene; DNPs: dinitropyrenes; 9-NA: 9-nitroanthracene; 1-NP: 1-nitropyrene.

of all sampling sites. In the heating seasons, the most abundant PAHs were FR and Pyr at all sites in every year. By contrast, in the non-heating seasons, the most abundant PAHs were BbF and BgPe. Among NPAHs, 9-NA was the most abundant at all sites in both in the heating and non-heating seasons from 2004 to 2010. The average concentrations of nine PAHs ranged from 730 to $1230 \mathrm{pmol} / \mathrm{m}^{3}$ in the heating seasons and ranged from 20.2 to $84.0 \mathrm{pmol} / \mathrm{m}^{3}$ in the non-heating seasons. The average concentrations of five NPAHs ranged from 1480 to $3200 \mathrm{fmol} / \mathrm{m}^{3}$ in the heating seasons and ranged from 120 to $2900 \mathrm{fmol} / \mathrm{m}^{3}$ in the nonheating seasons. Both PAH and NPAH concentrations were remarkably higher in the heating season than in the non-heating season at each site, in agreement with other reports in Beijing (Huang et al., 2006; Li et al., 2015; Zhou et al., 2005). Possible causes for the seasonal variation include the large amount of emissions from solid fuel combustion for residential heating in winter ( $\mathrm{Li}$ et al., 2015; Tang et al., 2005, 2011), the formation of a temperature inversion in the boundary layer in winter and photochemical degradation of NPAHs in summer (Fan et al., 1996; Fujitani, 1986). There is evidence that the air pollutants including PAHs in Beijing in winter were occasionally transported from industrial areas from Hebei, Inner Mongolia, Shanxi province (Lin et al., 2015; Liu et al., 2007; Wang et al., 2008).

The average concentrations of the nine PAHs at site 1, an urban site, from Nov. 25 to Dec. 21, 2009 (heating season) and from Aug. 11 to Sep. 1, 2010 (non-heating season) were higher than those at site 2, a suburban site, from Jan. 20 to 31, 2010 (heating season) and from Aug. 2 to 16, 2010 (non-heating season), respectively. However, these differences were not statistically significant $(n=7$, $p=0.44$ and 0.32 in heating season and non-heating season, respectively). The average concentrations of 1-NP were higher at site 1 but the average concentrations of 9-NA were higher at site 2 in both seasons. In contrast to atmospheric 1-NP, 9-NA not only originated from imperfect combustion of fossil fuels, but is also formed in the atmosphere via reaction of its parent PAH (AmadorMuñoz et al., 2011; Feilberg et al., 2001; Hayakawa et al., 1995; Lin et al., 2015; Zhang et al., 2011). And, no strong source of air pollutant are close to site 2. Therefore, atmospheric PAHs and NPAHs at site 2 were very likely to come from other areas in both seasons (Liu et al., 2007; Tao et al., 2007; Wang et al., 2008).

\subsection{Yearly variation of PAHs and NPAHs at site 1}

Table 3 shows the average concentrations of PAHs and NPAHs in Beijing from 2004 to 2010. Both PAHs and NPAHs levels at site 1 decreased from 2005 to 2010. Compared with data obtained in 2005 , the average concentrations of PAHs and NPAHs decreased by $72.6 \%$ and $93.4 \%$, respectively ( $n=7$ in 2010; $n=15$ in 2005, $p<0.01$ ). The same trend of atmospheric PAHs at urban sites in Beijing has been reported. For example, the average concentrations of the same nine PAHs were $225 \mathrm{ng} / \mathrm{m}^{3}$ from 2005 to 2007 (Wang et al., 2009) and were $96.5 \mathrm{ng} / \mathrm{m}^{3}$ from 2008 to 2009 (Ma et al., 2011). The other pollutants such as $\mathrm{PM}_{10}, \mathrm{NO}_{2}$ and $\mathrm{SO}_{2}$ also decreased in Beijing from 2004 to 2010 (Table 1). Vehicle exhaust is a more important source of PAHs in summer in Beijing than other sources, such as coal combustion and biomass combustion (Chen et al., 2015; Feng et al., 2005; Huang et al., 2006; Jiang et al., 2009; Wang et al., 2009; Zhou et al., 2005). Recent report also showed that the high numbers of motor vehicles caused higher NPAHs concentrations in Beijing (Li et al., 2015). However, the numbers of registered cars in Beijing more than doubled between 2005 and 2010 (Table 1).

As a possible cause for the decrease of atmospheric PAHs and NPAHs in the non-heating season were source control measures implemented by the city of Beijing before the 2008 Summer Olympic Games. These included new vehicle emission standards (European emission standards (Euro) III from 2005 and Euro IV from 2008) and restrictions on the use of vehicles (MEPB). The source control measures are still in effect.

By contrast, as shown in Table 3, in the heating season, only the average concentration of NPAHs at site 1 decreased from 2004 to 2009. Compared with data obtained in 2004, the average concentrations of NPAHs decreased by $53.7 \%(p<0.01)$. Because the yield of NPAHs from coal stove and/or boiler are smaller than that from vehicle (Tang et al., 2005) and DNPs and 1-NP in the atmosphere are mainly emitted from diesel-engine vehicles (Hayakawa et al., 1995), this result suggested that the source control measures were more effective against NPAHs than PAHs in the heating season. On the other hand, the average concentrations of PAHs at site 1 decreased from 2004 to 2008 ( $p=0.68$ ) but increased from 2008 to 2009 ( $p=0.19$ ), although these yearly variations were not 
significant. The coal combustion systems for domestic heating seemed to be the major contributors to the higher PAH levels in the heating season, in agreement with other reports (Feng et al., 2005; Hayakawa et al., 2007; He et al., 2006; Hou et al., 2006; Huang et al., 2006; Jiang et al., 2009; Liu et al., 2007; Wang et al., 2008; Zhang et al., 2009; Zhou et al., 2005). However, another improvement was the increasing use of natural gas in place of coal in winter in Beijing. In the present study, two days back trajectory was calculated during our 2009 heating season sampling period (online program provided by Air Resources Laboratory, NOAA). As shown in Fig. 2, high concentrations of PAHs were observed in the shorter trajectories, which means low wind speed, and these shorter trajectories originated from Hebei and Liaoning provinces on Nov. 27 (Fig. 2-(A), PAHs: $1940 \mathrm{pmol} / \mathrm{m}^{3}$ ) and from Shanxi province on Dec. 7 (Fig. 2-(B), PAHs: $2800 \mathrm{pmol} / \mathrm{m}^{3}$ ), which are the regions with heavy air pollutants (Li et al., 2015; Streets et al., 2007). On the other hand, low concentrations of PAHs were observed in the longer trajectories, such as on Dec. 16 (PAHs: $524 \mathrm{pmol} / \mathrm{m}^{3}$ ) and Dec. 18 (PAHs: $260 \mathrm{pmol} / \mathrm{m}^{3}$ ) (Fig. 2-(C)), suggesting that the air pollutants that originated locally were diffused by the high wind speed and diluted by relatively fresh air that came directly from the higher altitudes. The Air Pollution Index (API) values were 132, 141, 55 and 42 on Nov. 27, Dec. 7, 16 and 18, 2009, respectively (BMEPB), and showed the same trend with our PAHs data. Therefore, the high concentrations of PAHs at site 1 during our sampling period in 2009 have been influenced also by surrounding cities and provinces.

\subsection{Source indicators of PAHs and NPAHs}

The diagnostic ratios of several PAHs and NPAHs in the atmosphere have previously been used to indicate the main sources of the PAHs and NPAHs. Combustion of pertroleum products, such as gasoline and diesel fuel have smaller ratios of $[\mathrm{BaA}] /([\mathrm{Chr}]+[\mathrm{BaA}])$, $[\mathrm{BaP}] /([\mathrm{BaP}]+[\mathrm{BgPe}])$ and $[1-\mathrm{NP}] /[\mathrm{Pyr}]$ (Masclet et al., 1986; Simcik et al., 1999; Tang et al., 2005), while combustion of coal, such as in stoves, have large these ratios (Table 4) (Daisey et al., 1979; Tang et al., 2005). In this study, $[\mathrm{BaA}] /([\mathrm{Chr}]+[\mathrm{BaA}])$ and $[\mathrm{BaP}] /$ $([\mathrm{BgPe}]+[\mathrm{BaP}])$ ratios (Table 5$)$, indicate that the major contributors of atmospheric PAHs and NPAHs in Beijing were coal combustion in the heating season and vehicle emissions in the non-heating season.

On the other hand, the $[\mathrm{BbF}] /([\mathrm{BbF}]+[\mathrm{BkF}]),[\mathrm{FR}] /([\mathrm{FR}]+[\mathrm{Pyr}])$, $[\mathrm{IDP}] /([\mathrm{IDP}]+[\mathrm{BgPe}])$ and $[1-\mathrm{NP}] /[\mathrm{Pyr}]$ ratios were between in vehicle emission and in coal combustion (Tables 4 and 5), suggest that the mixing of these sources contributed to atmospheric PAHs and NPAHs in Beijing in each season although coal combustion was the main source in the heating season whereas vehicle emissions were the main source in the non-heating season, in agreement with other reports (Feng et al., 2005; Huang et al., 2006; Jiang et al., 2009; Wang et al., 2009; Zhou et al., 2005).

\subsection{Fate of atmospheric PAHs and NPAHs}

Atmospheric PAHs and NPAHs mainly originate from imperfect combustion and pyrolysis of organic matters (Chen et al., 2005; Hayakawa et al., 1995; Huang et al., 2014; Tang et al., 2005; Zhang et al., 2008). PAHs and NPAHs exist in both the gas and particle phases in the atmosphere. In general, PAHs having 2 rings exist in the gas phase, PAHs having 5 rings and NPAHs having 4 rings or more exist in the particle phase, and PAHs having 3 and 4 rings and NPAHs having 2 and 3 rings are in both phases (Araki et al., 2009; Tao et al., 2007; Yamasaki et al., 1982). When PAHs and NPAHs were exhausted to the atmosphere, their fates were influenced by various chemical and physical processes. Heterogeneous or homogeneous reactions of parent PAHs with nitrogen
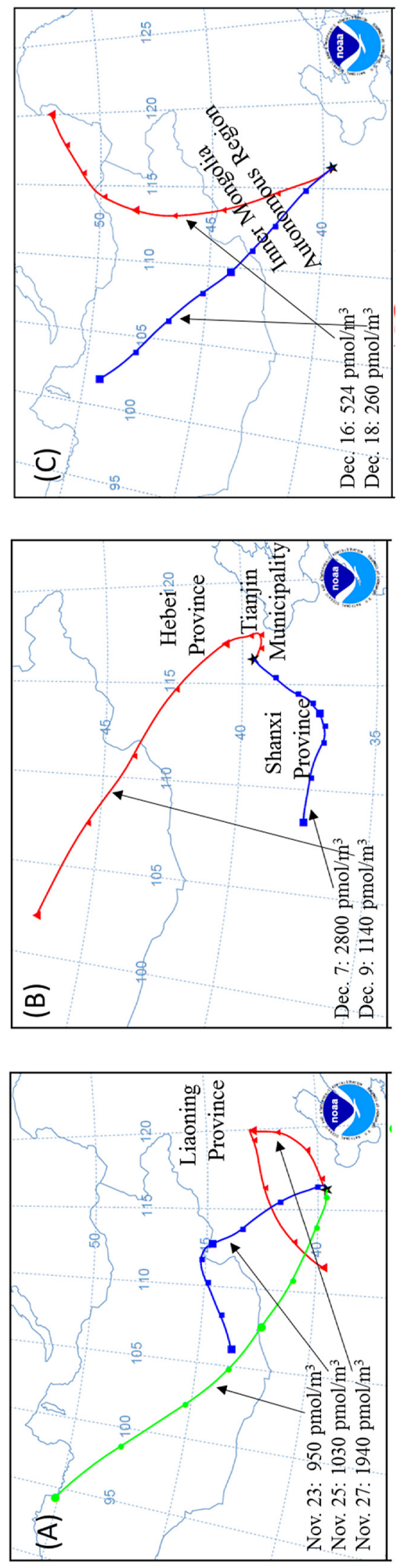
Table 4

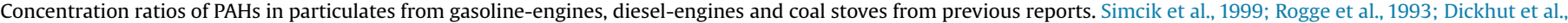
2000; Khalili et al., 1995; Sicre et al., 1987; Tang et al., 2005; Masclet et al., 1987; Zhang et al., 2008; Daisey et al., 1979 ; Chen et al., 2005 ; Huang et al., 2014.

\begin{tabular}{|c|c|c|c|c|c|c|}
\hline Source & {$[\mathrm{BaA}] /([\mathrm{Chr}]+[\mathrm{BaA}])$} & {$[\mathrm{FR}] /([\mathrm{Pyr}]+[\mathrm{FR}])$} & {$[\mathrm{BbF}] /([\mathrm{BbF}]+[\mathrm{BkF}])$} & {$[\mathrm{BaP}] /([\mathrm{BaP}]+[\mathrm{BgPe}])$} & {$[\mathrm{IDP}] /([\mathrm{BgPe}]+[\mathrm{IDP}])[1-\mathrm{NP}] /[\mathrm{Pyr}]$} & Reference \\
\hline Gasoline-engine & {$[\quad 0.22-0.55$} & 0.40 & $0.52-0.60$ & & $0.21-0.22$ & $\begin{array}{l}\text { Simcik et al., } 1999 \\
\text { Rogge et al., } 1993 \\
\text { Dickhut et al., } 2000 \\
\text { Khalili et al., } 1995\end{array}$ \\
\hline Diesel-engine & $\begin{array}{c}0.38-0.64 \\
0.36\end{array}$ & $\begin{array}{c}0.60-0.70 \\
0.50\end{array}$ & & $0.23-0.28$ & $\begin{array}{c}0.35-0.70 \\
0.50\end{array}$ & $\begin{array}{l}\text { Sicre et al., } 1987 \\
\text { Rogge et al., } 1993 \\
\text { Tang et al., } 2005 \\
\text { Masclet et al., } 1987\end{array}$ \\
\hline Coal stove & 0.50 & 0.53 & $\begin{array}{l}0.81-0.95 \\
0.78-0.80\end{array}$ & $0.47-0.86$ & $\begin{array}{c}0.33 \\
0.35-0.69 \\
0.23-0.47 \\
0.14-0.32\end{array}$ & $\begin{array}{l}\text { Tang et al., } 2005 \\
\text { Zhang et al., } 2008 \\
\text { Daisey et al., } 1979 \\
\text { Chen et al., } 2005 \\
\text { Huang et al., } 2014 \\
\text { Masclet et al., } 1987\end{array}$ \\
\hline
\end{tabular}

Table 5

Diagnostic ratios of several PAHs and NPAH in the atmosphere at two sites in Beijing.

\begin{tabular}{|c|c|c|c|c|c|c|c|}
\hline & & {$[\mathrm{BaA}] /([\mathrm{Chr}]+[\mathrm{BaA}])$} & {$[\mathrm{FR}] /([\mathrm{Pyr}]+[\mathrm{FR}])$} & {$[\mathrm{BbF}] /([\mathrm{BbF}]+[\mathrm{BkF}])$} & {$[\mathrm{BaP}] /([\mathrm{BaP}]+[\mathrm{BgPe}])$} & {$[\mathrm{IDP}] /([\mathrm{BgPe}]+[\mathrm{IDP}])$} & {$[1-\mathrm{NP}] /[\mathrm{Pyr}]$} \\
\hline \multirow[t]{6}{*}{ Site 1} & Dec., 2004 & 0.51 & 0.51 & 0.70 & 0.55 & 0.38 & 0.006 \\
\hline & Jan., 2008 & 0.56 & 0.51 & 0.76 & 0.38 & 0.31 & 0.005 \\
\hline & Nov., 2009 & 0.52 & 0.52 & 0.71 & 0.72 & 0.68 & 0.002 \\
\hline & May, 2005 & 0.40 & 0.53 & 0.72 & 0.42 & 0.40 & 0.011 \\
\hline & Aug., 2007 & 0.37 & 0.52 & 0.74 & 0.29 & 0.36 & 0.021 \\
\hline & Aug., 2008 & 0.31 & 0.53 & 0.76 & 0.38 & 0.50 & 0.019 \\
\hline \multirow[t]{2}{*}{ Site 2} & Jan., 2010 & 0.43 & 0.50 & 0.55 & 0.67 & 0.61 & 0.001 \\
\hline & Aug., 2010 & 0.41 & 0.52 & 0.71 & 0.37 & 0.40 & 0.015 \\
\hline
\end{tabular}

oxides and hydroxyl radicals decreased the parent PAHs and increased their nitro-, oxy- and hydroxyl derivatives in the atmosphere (Amador-Muñoz et al., 2011; Arey et al., 1986; Feilberg et al., 2001; Kameda et al., 2011). Dry and wet deposition processes can effectively remove particulate PAHs and NPAHs from the atmosphere (Bidleman, 1988). In this study, we examined the effects of two physical factors, wind speed $(\mathrm{m} / \mathrm{s})$ and relative humidity (\%), to evaluate the directly effects to the atmospheric concentrations of PAHs and NPAHs in the different season in Beijing. Strong and negative correlations were found between all PAH and NPAH levels and wind speed in heating season $(n=34, p<0.01$ for all PAHs and DNPs and $p<0.05$ for $1-\mathrm{NP}$ ) (Table 6 ). However, the correlation was weak for DNPs, and no correlation was observed in the non-heating season. The negative correlations between PAH and NPAH levels and wind speed may have been due to the high wind speed (Table 2), which is generally associated with clean air from higher altitudes in the heating season, as discussed in section 3.2. High relative humidity led to decreases in the concentrations of PAHs and NPAHs in the non-heating season, in agreement with other reports (Hong et al., 2007; Park et al., 2002; Zhu et al., 2014), whereas it led to increases in PAH and NPAH levels, except for 9-NA, in the heating season. The negative correlation between relative humidity and wind speed in the heating season was strong ( $n=34$, $r=-0.6873, p<0.01$ ), which suggests that low wind speed reduced the diffusion of PAHs and NPAHs originating from domestic sources. 9-NA originates from both direct emissions and heterogeneous reactions in the atmosphere on particulate-bound anthracene and nitrating agents (Amador-Muñoz et al., 2011; Feilberg et al., 2001; Lin et al., 2015; Zhang et al., 2011). Therefore, the atmospheric behavior of 9-NA cannot be explained by only physical parameters used in this study.

\section{Conclusions}

In this study, the behaviours of atmospheric PAHs and NPAHs were investigated at two sites in Beijing from 2004 to 2010. The concentrations of PAHs and NPAHs were higher in the heating season in every year at both sites. The concentrations of both PAHs and NPAHs decreased in the non-heating season but only the concentrations of NPAHs decreased in the heating season at site 1 , which is an urban site. Moreover, the yearly average concentrations of $\mathrm{PM}_{10}, \mathrm{SO}_{2}$ and $\mathrm{NO}_{2}$ decreased in Beijing from 2004 to 2010 (Table 1). These observations suggest that source control measures

Table 6

Correlation coefficients between nine PAHs, six NPAHs and several meteorological factors at two sites in the heating and non-heating seasons.

\begin{tabular}{llllll}
\hline \multirow{2}{*}{ Compound } & \multicolumn{2}{c}{ Wind flow $(\mathrm{m} / \mathrm{s})$} & & \multicolumn{2}{c}{ Relative humidity (\%) } \\
\cline { 2 - 3 } \cline { 5 - 6 } & Heating & Non-heating & & Heating & Non-heating \\
\hline FR & $-0.5375^{* *}$ & 0.0496 & & 0.3084 & -0.0979 \\
Pyr & $-0.5446^{* *}$ & 0.0761 & & 0.2861 & -0.1031 \\
BaA & $-0.5968^{* *}$ & 0.1675 & & $0.4169^{*}$ & -0.2960 \\
Chr & $-0.5642^{* *}$ & 0.1229 & & $0.3995^{*}$ & -0.2477 \\
BbF & $-0.7790^{* *}$ & 0.0529 & & $0.5813^{* *}$ & -0.1538 \\
BkF & $-0.7362^{* *}$ & 0.1523 & & $0.5443^{* *}$ & -0.2656 \\
BaP & $-0.6769^{* *}$ & 0.1863 & & $0.4043^{*}$ & -0.3329 \\
BgPe & $-0.5038^{* *}$ & 0.1364 & & 0.1817 & -0.2544 \\
IDP & $-0.5132^{* *}$ & 0.2156 & & 0.2402 & -0.2346 \\
DNPs & $-0.5559^{* *}$ & 0.1953 & & $0.4742^{* *}$ & $-0.4048^{*}$ \\
9-NA & -0.071 & 0.1312 & & $-0.3820^{*}$ & $-0.4769^{* *}$ \\
1-NP & $-0.4268^{*}$ & -0.0594 & $0.3946^{*}$ & -0.1170 \\
\hline
\end{tabular}

Level of significance: ${ }^{*}: p<0.05 ;{ }^{* *}: p<0.01 . n=34$ in heating season and $n=36$ in non-heating season. 
implemented by the city of Beijing had a positive effect on the Beijing air pollution. The concentrations of PAHs increased at site 1 in 2010, possibly due to transposition of emission from other areas, such as Shanxi province. Diagnostic ratios of atmospheric PAHs and NPAHs showed that the mixed sources contributed to atmospheric pollution in Beijing, although coal combustion was the main source in the heating season and vehicle emissions were the main source in the non-heating season. Our results also show that atmospheric PAHs and NPAHs in Beijing can be removed by high wind speeds in the heating season and by high relative humidity in the nonheating season.

\section{Acknowledgements}

This research was supported in part by a Grant in Aid for Scientific Research (Nos. 21256001, 21120503, 21590132, 23406004, 24590769 and 24406020) from the Ministry of Education, Culture, Sports, Science, the Global Environment Research Fund from the Ministry of Environment, Japan (5-1306) and National Natural Science Foundation of China (No. 21677152). We gratefully acknowledge the Air Resources Laboratory, NOAA for the provision of the HYSPIT.

\section{References}

Amador-Muñoz, O., Villalobos-Pietrini, R., Miranda, J., Vera-Avila, L.E., 2011. Organic compounds of PM2.5 in Mexico Valley: spatial and temporal patterns, behavior and sources. Sci. Total Environ. 409, 1453-1465.

Ames, B.N., McCann, J., Yamasaki, E., 1975. Methods for detecting carcinogens and mutagens with the salmonella/mammalian-microsome mutagenicity test. Mutat. Res. 31, 347-364.

Araki, Y., Tang, N., Ohno, M., Kameda, T., Toriba, A., Hayakawa, K., 2009. Analysis of atmospheric polycyclic aromatic hydrocarbons and nitropolycyclic aromatic hydrocarbons in gas/particle phases separately collected by a high-volume air sampler equipped with a column packed with XAD-4 resin. J. Health Sci. 55, 77-85.

Arey, J., Zielinska, B., Atkinson, R., Winer, A.M., Ramdahl, T., Pitts, J.N., 1986. The formation of nitro-PAH from the gas-phase reactions of fluoranthene and pyrene with the $\mathrm{OH}$ radical in the presence of NOx. Atmos. Environ. 20, 2339-2345.

Bidleman, T.F., 1988. Atmospheric processes: wet and dry deposition of organic compunds are controlled by their vapor-particle partitioning. Environ. Sci. Technol. 22, 361-367.

BMEPB, Beijing Municipal Environmental Protection Bureau(http://www.bjepb.gov. cn/bjepb/399216/index.html).

Chen, B., Yamada, M., Iwasaka, Y., Zhang, D.Z., Wang, H., Wang, Z.Z., Lei, H.C., Shi, G.Y., 2015. Origin of non-spherical particles in the boundary layer over Beijing, China: based on balloon-borne observations. Environ. Geochem. Health 37, $791-800$.

Chen, Y., Sheng, G., Bi, X., Feng, Y., Mai, B., Fu, J., 2005. Emission factors for carbonaceous particles and polycyclic aromatic hydrocarbons from residential coal combustion in China. Environ. Sci. Technol. 39, 1861-1867.

Daisey, J.M., Keyko, M.H., Kneip, T.J., 1979. Source identification and allocation of polycyclic aromatic hydrocarbon compounds in the New York city aerosol: methods and applications. In: Jones, P.W., Leber, P. (Eds.), Polycyclic Aromatic Hydrcarbons, vol. 99, pp. 201-215. Ann Arbor Science, Ann arbor.

Dickhut, R.M., Canuel, E.A., Gustafson, K.E., Liu, K., Arzayue, K.M., Walker, S.E., Edgecombe, G., Gaylor, M.O., Macdonald, E.H., 2000. Automotive sources of carcinogenic polycyclic aromatic hydrocarbons associated with particulate matter in the Chesapeake bay region. Environ. Sci. Technol. 34, 4635-4640.

Epstein, S.S., Fujii, K., Asahina, S., 1979. Carcinogenicity of a composite organic extract of urban particulate atmospheric pollutants following subcutaneous injection in infant mice. Environ. Res. 19, 163-176.

Fan, Z.H., Kamens, R.M., Hu, J.X., Zhang, J.B., McDow, S., 1996. Photostability of nitropolycyclic aromatic hydrocarbons on combustion soot particles in sunlight. Environ. Sci. Technol. 30, 1358-1364.

Feng, J., Chan, C.K., Fang, M., Hu, M., He, L., Tang, X., 2005. Impact of meteorology and energy structure on solvent extractable organic compounds of PM2.5 in Beijing, China. Chemosphere 61, 623-632.

Feilberg, A., Poulsen, M.W.B., Nielsen, T., Skov, H., 2001. Occurrence and sources of particulate nitro-polycyclic aromatic hydrocarbons in ambient air in Denmark. Atmos. Environ. 35, 353-366.

Fujitani, T., 1986. Seasonal variation of the structure of the atmospheric boundary layer over a suburban area. Atmos. Environ. 20, 1867-1876.

Gachanja, A.N., Worsfold, P.J., 1993. Monitoring of polycyclic aromatic hydrocarbon emissions from biomass combustion in Kenya using liquid chromatography with fluorescence detection. Sci. Total Environ. 138, 77-89.
Hattori, T., Tang, N., Tamura, K., Hokoda, A., Yang, X., Igarashi, K., Ohno, M., Okada, Y., Kameda, T., Toriba, A., Hayakawa, K., 2007. Particulate polycyclic aromatic hydrocarbons and their nitrated derivatives in three cities in Liaoning Province, China. Environ. Forensics 8, 165-172.

Hayakawa, K., Kitamura, R., Butoh, M., Imaizumi, N., Miyazaki, M., 1991. Determination of diamino- and aminopyrenes by high performance liquid chromatography with chemiluminescence detection. Anal. Sci. 7, 573-577.

Hayakawa, K., Murahashi, T., Butoh, M., Miyazaki, M., 1995. Determination of 1,31,6-, and 1,8-dinitropyrenes and 1-nitropyrene in urban air by highperformance liquid chromatography using chemiluminescence detection. Environ. Sci. Technol. 29, 928-932.

Hayakawa, K., Tang, N., Kameda, T., Toriba, A., 2007. Atmospheric behaviors of polycyclic aromatic hydrocarbons and nitropolycyclic aromatic hydrocarbons in East Asia. Asian J. Atmos. Environ. 1, 19-27.

He, L.Y., Hu, M., Huang, X.F., Zhang, Y.H., Tang, X.Y., 2006. Seasonal pollution characteristics of organic compounds in atmospheric fine particles in Beijing. Sci. Total Environ. 359, 167-176.

Hou, X.M., Zhuang, G.S., Sun, Y., An, Z.S., 2006. Characteristics and sources of polycyclic aromatic hydrocarbons and fatty acids in PM2.5 aerosols in dust season in China. Atmos. Environ. 40, 3251-3262.

Hong, H.S., Yin, H.L., Wang, X.H., Ye, C.X., 2007. Seasonal variation of PM10-bound PAHs in the atmosphere of Xiame, China. Atmos. Res. 85, 429-441.

Huang, X.F., He, L.Y., Hu, M., Zhang, Y.H., 2006. Annual variation of particulate organic compounds in PM2.5 in the urban atmosphere of Beijing. Atmos. Environ. 40, 2449-2458.

Huang, W., Huang, B., Bi, X.H., Lin, Q.H., Liu, M., Ren, Z.F., Zhang, G.H., Wang, X.M., Sheng, G.Y., Fu, J.M., 2014. Emission of PAHs, NPAHs and OPAH from residential honeycomb coal briquette combustion. Energy fuels. 28, 636-642.

IARC Monographs of the evaluation of carcinogenic risks to humans, 2013. Diesel and Gasoline Engine Exhausts, vol. 105. World Health Organization, International Agency for Research on Cancer, Lyon, France.

Jiang, Y.L., Hou, X.M., Zhuang, G.S., Li, J., Wang, Q.Z., Zhang, R., Lin, Y.F., 2009. The sources and seasonal variations of organic compounds in PM2.5 in Beijing and Shanghai. J. Atmos. Chem. 62, 175-192.

Kameda, T., Akiyama, A., Toriba, A., Tang, N., Hayakawa, K., 2011. Atmospheric formation of hydroxynitropyrenes from a photochemical reaction of particleassociated 1-nitropyrene. Environ. Sci. Technol. 45, 3325-3332.

Kavouras, I.G., Koutrakis, P., Tsapakis, M., Lagoudaki, E., Stephanou, E.G., Von Baer, D., Oyola, P., 2001. Source apportionment of urban particulate aliphatic and polynuclear aromatic hydrocarbons (PAHs) using multivariate methods. Environ. Sci. Technol. 35, 2288-2294.

Khalili, N.R., Scheff, P.A., Holsen, T.M., 1995. PAH source fingerprints for coke ovens diesel and, gasoline engines, highway tunnels, and wood combustion emissions. Atmos. Environ. 29, 533-542.

Kizu, R., Ishii, K., Kobayashi, J., Hashimoto, T., Koh, E., Namiki, M., Hayakawa, K. 2000. Antiandrogenic effect of crude extract of C-heavy oil. Mater. Sci. Eng. C 12, 97-102.

Li, W., Wang, C., Shen, H.Z., Su, S., Shen, G.F., Huang, Y., Zhang, Y.Y., Chen, Y.C., Chen, H., Lin, N., Zhuo, S.J., Zhong, Q.R., Wang, X.L., Liu, J.F., Li, B.G., Liu, W.X., Tao, S., 2015. Concentrations and origins of nitro-polycyclic aromatic hydrocarbons and oxy-polycyclic aromatic hydrocarbons in ambient air in urban and rural area in northern China. Environ. Pollut. 197, 156-164.

Lin, Y., Qiu, X.H., Ma, Y.Q., Ma, J., Zheng, M., Shao, M., 2015. Concentrations and spatial distribution of polycyclic aromatic hydrocarbons (PAHs) and nitrated PAHs (NPAHs) in the atmosphere of North China, and the transformation from PAHs to NPAHs. Environ. Pollut. 196, 164-170.

Liu, S.Z., Tao, S., Liu, W.X., Liu, Y.N., Dou, H., Zhao, J.Y., Wang, L.G., Wang, J.F., Tian, Z.F., Gao, Y., 2007. Atmospheric polycyclic aromatic hydrocarbons in north China: a winter-time study. Environ. Sci. Technol. 41, 8256-8261.

Ma, W.L., Sun, D.Z., Shen, W.G., Yang, M., Qi, H., Liu, L.Y., Shen, J.M., Li, Y.F., 2011. Atmospheric concentrations, sources and gas-particle partitioning of PAHs in Beijing after the $29^{\text {th }}$ Olympic Games. Environ. Pollut. 159, 1794-1801.

Masclet, P., Bresson, M.A., Mouvier, G., 1987. Polycyclic aromatic hydrocarbons emitted by power stations and influence of combustion conditions. Fuel 66 556-562.

Masclet, P., Mouvier, G., Nikolaou, K., 1986. Relative decay index and sources of polycyclic aromatic hydrocarbons. Atmos. Environ. 20, 439-446.

Motoyama, Y., Bekki, K., Chung, S.W., Tang, N., Kameda, T., Toriba, A., Taguchi, K., Hayakawa, K., 2009. Oxidative stress more strongly induced by ortho- than para-quinoid polycyclic aromatic hydrocarbons in A549 cells. J. Health Sci. 55, 850-854.

Park, S.S., Kim, Y.J., Kang, C.H., 2002. Atmospheric polycyclic aromatic hydrocarbons in Seoul, Korea. Atmos. Environ. 36, 2917-2924.

Perera, F.P., Tang, D., Wang, S., Vishnevetsky, J., Zhang, B., Diaz, D., Camann, D., Rauh, V., 2012. Prenatal polycyclic aromatic hydrocarbon (PAH) exposure and child behavior at age 6-7 years. Environ. Health Perspect. 120, 921-926.

Rogge, W.F., Hildemann, L.M., Mazurek, M.A., Cass, G.R., Simoneit, B.R.T., 1993. Sources of fine organic aerosol. 2. Noncatalyst and catalyst-equipped automobiles and heavy-duty diesel trucks. Environ. Sci. Technol. 27, 636-651.

Sicre, M.A., Marty, J.C., Saliot, A., Aparicio, X., Grimalt, J., Albaiges, J., 1987. Aliphatic and aromatic hydrocarbons in different sized aerosols over the Mediterranean Sea: occurrence and origin. Atmos. Environ. 21, 2247-2259.

Simcik, M.F., Eisenreich, S.J., Lioy, P.J., 1999. Source apportionment and source/sink relationships of PAHs in the coastal atmosphere of Chicago and Lake Michigan. Atmos. Environ. 33, 5071-5079. 
Sitaras, I.E., Bakeas, E.B., Siskos, P.A., 2004. Gas/particle partitioning of seven volatile polycyclic aromatic hydrocarbons in a heavy traffic urban area. Sci. Total Environ. 327, 249-264.

Streets, D.G., Fu, J.S., Jang, C.J., Hao, J.M., He, K.B., Tang, X.Y., Zhang, Y.H., Wang, Z.F. Li, Z.P., Zhang, Q., Wang, L.T., Wang, B.Y., Yu, C., 2007. Air quality during the 2008 Beijing olympic games. Atmos. Environ. 41, 480-492.

Tang, N., Toriba, A., Kizu, R., Hayakawa, K., 2003. Improvement of an automatic HPLC system for nitropolycyclic aromatic hydrocarbons: removal of an interfering peak and increase in the number of analytes. Anal. Sci. 19, 249-253.

Tang, N., Hattori, T., Taga, R., Igarashi, K., Yang, X.Y., Tamura, K., Kakimoto, H., Mishukov, V.F., Toriba, A., Kizu, R., Hayakawa, K., 2005. Polycyclic aromatic hydrocarbons and nitropolycyclic aromatic hydrocarbons in urban air particulates and their relationship to emission sources in the Pan-Japan Sea countries. Atmos. Environ. 39, 5817-5826.

Tang, N., Tokuda, T., Izzaki, A., Tamura, K., Ji, R.A., Zhang, X.M., Dong, L.J., Kameda, T. Toriba, A., Hayakawa, K., 2011. Recent changes in atmospheric polycyclic aromatic hydrocarbons (PAHs) and nitropolycyclic aromatic hydrocarbons (NPAHs) in Shenyang, China. Environ. Forensics 12, 342-348.

Tao, S., Wang, Y., Wu, S.M., Liu, S.Z., Dou, H., Liu, Y.N., Lang, C., Hu, F., Xing, B.S., 2007. Vertical distribution of polycyclic aromatic hydrocarbons in atmospheric boundary layer of Beijing in winter. Atmos. Environ. 41, 9594-9602.

Wang, H.L., Zhou, Y.M., Zhuang, Y.H., Wang, X.K., Hao, Z.P., 2009. Characteriztion of PM2.5/PM2.5-10 and source tracking in the juncture belt between urban and rural areas of Beijing. Chin. Sci. Bull. 54, 2506-2515.

Wang, X.F., Cheng, H.X., Xu, X.B., Zhuang, G.M., Zhao, C.D., 2008. A wintertime study of polycyclic aromatic hydrocarbons in $\mathrm{PM}_{2.5}$ and $\mathrm{PM}_{25-10}$ in Beijing: assessment of energy structure conversion. J. Hazard. Mater. 157, 47-56.

Wang, W.T., Jariyasopit, N., Schrlau, J., Jia, Y., Tao, S., Yu, T.W., Dashwood, R.H., Zhang, W., Wang, X., Simonich, S.L., 2011. Concentration and photochemistry of PAHs, NPAHs, and OPAHs and toxicity of PM (2.5) during the Beijing olympic games. Environ. Sci. Technol. 45, 6887-6895.

Yamasaki, H., Kuwata, K., Miyamoto, H., 1982. Effect of ambient temperature on aspects of airborne polycyclic aromatic hydrocarbons. Environ. Sci. Technol. 16, 189-194.

Zhang, S.C., Zhang, W., Wang, K.Y., Shen, Y.T., Hu, L.W., Wang, X.J., 2009. Concentration, distribution and source apportionment of atmospheric polycyclic aromatic hydrocarbons in the southeast suburb of Beijing, China. Environ. Monit. Assess. 151, 197-207.

Zhang, Y., Yang, B., Gan, J., Liu, C.G., Shu, X., Shu, J.N., 2011. Nitration of particleassociated PAHs and their derivatives (nitro-, oxy-, and hydroxy-PAHs) with $\mathrm{NO}_{3}$ radicals. Atmos. Environ. 45, 2515-2521.

Zhang, Y.X., Schauer, J.J., Zhang, Y.H., Zeng, L.M., Wei, Y.J., Liu, Y., Shao, M., 2008. Characteristics of particulate carbon emissions from real-world Chinese coal combustion. Environ. Sci. Technol. 42, 5073-5268.

Zhou, J., Wang, T., Huang, Y., Mao, T., Zhong, N., 2005. Size distribution of polycyclic aromatic hydrocarbons in urban and suburban sites of Beijing, China. Chemosphere 61, 792-799.

Zhu, Y.H., Yang, L.X., Yuan, Q., Yan, C., Dong, C., Meng, C.P., Sui, X., Yao, L., Yang, F., Lu, Y.L., Wang, W.X., 2014. Airborne particulate polycyclic aromatic hydrocarbon $(\mathrm{PAH})$ pollution in a background site in the North China plain: concentration, size distribution, toxicity and sources. Sci. Total Environ. 466-467, 357-368. 